BLS 33, No 1 2007. DOI: http://dx.doi.org/10.3765/bls.v33i1.3543

(published by the Berkeley Linguistics Society and the Linguistic Society of America)

\title{
The Eastern Tukanoan Languages and the Typology of Classifiers $^{1}$
}

\author{
WILSON SILVA and JOSHUA BOWLES \\ Center for American Indian Languages, University of Utah
}

\section{Introduction}

The Tukanoan ${ }^{2}$ languages have a complex system of noun classifiers. There have been several studies in individual Tukanoan languages (which include descriptions of their noun classifiers), such as Barnes (1990) for Tuyuca, Gomez-Imbert (2006) for Tatuyo, Ramirez (1997) for Tukano and Stenzel (2004) for Wanano. Other works ${ }^{3}$ also have mentioned the complexity of classifiers in Tukanoan languages, and they were also used as resources for this investigation. Due to the limitation of space, we give examples only in the languages which better illustrates the phenomena we discuss.

In this paper, we highlight some typological anomalies in the noun classifier $\left(\mathrm{NCL}\right.$ hereafter) ${ }^{4}$ systems of Eastern Tukanoan (ET) languages, taking into account the typology of NCL generally. The NCLS of ET exhibit behavior that challenges some current claims concerning the typology of classifiers. In section 1 we provide an overview of the properties of NCL; in 2 we test typological claims about classifiers; finally, in 3 we conclude by discussing the contributions that ET languages make to the general study of the typology of classifiers systems.

\footnotetext{
${ }^{1}$ This study is part of a larger project by the authors. We would like to thank Lyle Campbell for his comments on drafts of this paper. Of course the authors are fully responsible for any remaining errors. We also thank Sasha Aikhenvald for her insightful comments during the $33^{\text {rd }}$ BLS Meeting. ${ }^{2}$ According to Stenzel (2004:20), the Tukanoan family consists of 20 languages divided in two branches: Western (WT) and Eastern (ET). The WT languages are: Korenguaje, Secoya, Siona, and Orejón; and the ET languages are: Bará, Barasano, Desano, Karapanã, Kubeo, Makuna, Piratapuyo, Pisamira, Siriano, Retuarã, Taiwano, Tatuyo, Tuyuca, Tucano, Wanano and Yurití. The total number of speakers: 28,000 for all the languages together. These languages are spoken in areas of Brazil, Colombia, Ecuador, and Peru; known as Northwest Amazonia.

${ }^{3}$ Barasano (Jones and Jones, 1991), Cubeo (Fergunson et al., 2000; Morse and Maxwell, 1999), Siriano (Criswell and Brandrup, 2000), Tucano (Welch and West, 2000) Yurití (Kinch and Kinch, 2000), Desano (Miller, 1999), Retuarã (Strom, 1992), Karapanã (Metzger, 1981; Silva 2006),

${ }^{4}$ Abbreviations: $\mathrm{CL}=$ classifier; $\mathrm{ET}=$ Eastern Tukanoan; $\mathrm{GEN}=$ genitive; GENCL $=$ genitive classifier; $\mathrm{LCL}=$ locative classifier; $\mathrm{MASC}=$ masculine; $\mathrm{NCL}=$ noun classifier; $\mathrm{NUM}=$ number; $\mathrm{NUMCL}=$ numeral classifier; POSS $=$ possessive $; \mathrm{VCL}=$ verb classifier; $\mathrm{WT}=$ Western Tukanoan
} 
Wilson Silva \& Joshua Bowles

\section{Overview of Classifiers}

\subsection{Historical Background}

The description and study of nominal classification got its serious start in the mid 1960's with Burling (1965) and Berlin (1968). Both works were about numeral classifiers, the former in Burmese and the latter in Tzeltal. These were followed by later studies in Mayan (Tzeltal, Jakaltec, Akatek) and Austronesian languages, as well as in Thai, Vietnamese, Chinese, and Japanese. Allan (1975) is foundational for classifier studies, and Denny (1976) is one of the first to mention explicitly NCL as opposed to 'concordial' classifiers. The well-studied noun-class systems of Bantu languages were compared to the less grammaticalized forms of numeral or noun classifiers. Dixon $(1982,1986)$ compared noun-class systems with classifier systems in Yidiny and Dyribal, both Australian languages, and this work remains influential for NCLs. Craig (1986a, 1992) and Grinevald (2000) showed that a grammaticalization "continuum" from lexical (nouns and measure terms) to grammatical (gender or noun-class morphemes) is the best approach for observing noun classifiers in typological perspective. Finally, Aikhnevald (2000) attempted to formulate a large-scale typology of nominal classification systems, including verb, deictic, possessive, and noun classifiers, as well as 'multiple classifier' and various noun-class systems in the world's languages. The determining characteristic of NCLs is the fundamental distinction between them and a noun-class or gender markers. That is, NCL is not part of the agreement system. In more recent work on Tukanoan languages (Gomez-Imbert 2006) this distinction is being questioned.

In the following section we present the current typological model for noun classifiers based on Craig (1992) and Grinevald (2000) (see also Aikhenvald 2000) and discuss how ET classifiers fit into this typological model.

\subsection{Current Typological Properties ${ }^{5}$}

The function of NCL, according to Craig (1992) and Grinevald (2002), can be analyzed by three criteria: the operator context, the morphosyntactic environment, and the semantic domain. In her typology, different kinds of classifiers will exhibit unique behaviors according to the three criteria, as illustrated in Table 1, which presents the prototypical characteristics of classifiers according to Craig (1992) and Grinevald (2002).

\footnotetext{
${ }^{5}$ We have not yet looked in-depth at the classifier systems of other well-known languages such as Chinese, Japanese, Vietnamese, etc. Therefore, the above statements may not be representative of all the world's languages.
} 
The Eastern Tukanoan Languages and the Typology of Noun Classifiers

TABLE 1 - Prototypical Characteristics of Classifiers ${ }^{6}$ (Grinevald)

\begin{tabular}{|c|c|c|c|}
\hline TYPES OF CL & NUMCL & GENCL & NCL \\
\hline Operator context & [quantity] & [locality] & [quality] \\
\hline Morphosyntax & $\mathrm{NUM}+\mathrm{CL}$ & $\mathrm{POSS}+\mathrm{CL}$ & $\mathrm{CL}+\mathrm{NOUN}$ \\
\hline Semantic domain & type/shap & function & material/essence \\
\hline Example: & $\begin{array}{l}\text { tuhke rioapwoat } \\
\text { tree } 2+\mathrm{CL}: \text { long } \\
\text { 'two trees' } \\
\text { (Ponapean) }\end{array}$ & $\begin{array}{l}\text { kene-i mwenge } \\
\text { CL:edible-GEN/1 food } \\
\text { 'my food' } \\
\text { (Ponapean) }\end{array}$ & $\begin{array}{l}\text { naj xuwan } \\
\text { CL:man John } \\
\text { 'John' } \\
\text { (Jakalteko) }\end{array}$ \\
\hline
\end{tabular}

In Table 1, the NCL functions to individuate the noun by selecting salient features of the noun or some quality of the material/essence of that noun and preceding it within the noun phrase. For example, in Jakalateko naj xuwan 'man John' the NCL naj selects the quality and essence "animate human" in the noun xuwan 'John' while occupying the morphosyntactic position in front of the noun (Craig 1992:284). This is what gives the NCL its "individuating" function (Grinevald 2002:290). The use of NCL and classifiers in general is not an absolute requirement and many cases of data show that the NCL is not obligatorily required to occur compared to the obligatoriness of noun-classes (Aikhenvald 2000:81). However, in ET some nouns obligatorily need a NCL. ${ }^{8}$ The decision to use NCL with a noun is pragmatically decided based on the discourse context (Craig 1986a).

The unique function of individuating the noun by NCL, along with the reduced semantic content of the NCL (i.e. the general semantic domain of "material/essence") naj 'man,' places the NCL, according to Craig, closer to a grammatical category than a typical lexical noun. However, compared to noun-classes or gender markers, whose semantic content is almost entirely bleached and whose presence on the noun is absolutely required, NCL cannot be a fully grammatical item. Therefore, the NCL, and classifiers in general, fall somewhere between lexical items and grammatical items. This analysis is consistent with Dixon (1982) and Aikhenvald (2000). This continuum between lexical and grammatical items is shown in Grinveald (2002) and reproduced here in (1) with Wanano examples from Stenzel $(2004: 128,145)$.

(1) Grammaticalization Continuum (Grinevald 2002:260)

$<$ lexical.

grammatical>

$\begin{array}{ccc}\text { measure/class terms } \quad \text { "CLASSIFIERS" } & -k u & \text { noun class/gender }\end{array}$

$-k u$

$\mathrm{NCL}_{\text {tree }} \quad$ MASC

${ }^{6}$ Ponapean and Jakalteko data from Craig (1992:283-85).

${ }^{8}$ From an anonymous reviewer of grant proposal related to this topic (April 2007). 


\subsection{Noun Classifiers in ET Languages}

ET languages have classifiers of various types (VCL, LCL, GENCL, NUMCL and NCL) in various combinations. They also have a noun-class system. In this study we focus on NCL. There have been several studies to establish a distinction between a classifier and a noun-class in ET languages (Derbyshire and Payne 1990, Barnes 1990, Gomez-Imbert 1996, 2006). We believe that a distinction between NCL and noun-class does exist and the following data are a first approximation to our efforts to illustrate this distinction. Typologically, the NCL is non-obligatory and not an essential part of the gender or other agreement markers (case, tense, person, aspect, mood).

In ET languages NCLs are suffixed to the noun and their semantic domain includes "type/shape" as well as "material/essence." In the prototype typology for classifiers, also presented in Table1, based on Graig (1992) and Grinevald (2002), it was established that the semantic domain of NCLs is 'material/essence'. The examples (2)-(4) from selected ET languages show that NCLs also covers the semantic domain of 'type/shape.' Examples (a) reflect the domain of 'material/essence' and (b) show 'shape/type.'

Kubeo $^{9}$

(2)
a. hoki-ki
wood-NCL tree
'tree'

Wanano ${ }^{10}$

(3)

(3)

Desano $^{11}$

a. pari-taro-re

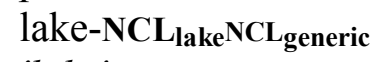

$$
\text { 'lake' }
$$

(4)

a.
banana-NCL $\mathbf{N} \mathbf{L}_{\text {palm }}$
'banana plant'

b. $\quad$ xia-jo- $\sim \mathrm{ku}$

river-NCL $\mathbf{L}_{\text {slender.pointed }} \mathrm{NCL}_{\text {hump.shaped }}$ 'canoe'

b. tua-du

stick-NCL $\mathbf{L}_{\text {cylindrical/straight }}$

'a branch'

b. $\quad$ b ata-soro

clay-NCL $\mathbf{L}_{\text {concave bowl }}$

'clay bowl'

The data presented do not fit in the prototypical typology presented in Table 1 . Thus, we propose a revision of the prototypical typology, as shown in Table 2, which accounts for NCL in ET languages. The changes are in boldface under NCL.

\footnotetext{
${ }^{9}$ Data from Morse and Maxwell (1999:75).

${ }^{10}$ Data from Stenzel $(2004: 144,411)$.

11 Data from Miller (1999:37, 41).
} 
The Eastern Tukanoan Languages and the Typology of Noun Classifiers

TABLE 2 - Prototypical Typology of ncl in ET.

\begin{tabular}{|l|c|c|c|}
\hline TYPES OF CL & NUMCL & GENCL & NCL \\
\hline Operator context & {$[$ quantity] } & {$[$ locality] } & [quality] \\
\hline Morphosyntax & NUM + CL & POSS + CL & NOUN + CL \\
\hline Semantic domain & type/shape & function & $\begin{array}{c}\text { material/essence } \\
\text { type/shape }\end{array}$ \\
\hline
\end{tabular}

In the following section, we discuss some of the general claims that have been made about classifiers and in particular about NCL; and we will show how data from ET languages fit into these claims.

\section{Some General Claims of NCL Systems}

In this section we present four general claims about classifiers that have been made in previous attempts to establish a typology of classifiers. For each claim (i)-(iii) we present data from selected ET languages. For the claims (i) and (iii) we present data that we believe are counter-examples. For claim (ii) we present data that pose possible problems, which we discuss.

(i) 'Noun classifiers are always free forms' (Dixon 1986:106). We find that in the agglutinating languages of ET ncl occurs as a suffix to the noun.

(ii) 'All occurrences of two generic nouns [NCL] in a noun phrase must involve one inherent nature term and one function/use classifier' (Dixon 1982:192). We find data that warrant doubt concerning this claim.

(iii) 'Noun classifier systems... have a large preference for one semantic cluster, that of material' (Grinevald 2000:73). Our data show that in ET this may not be the case.

In section 2.1 we deal with each claim separately.

\section{1. $\quad$ ET Languages and the Typology of Classifiers}

Claim (i) - 'Noun classifiers are always free forms' (Dixon, 1986:106). According to Dixon 'a classifier will occur in the same noun phrase as the noun it qualifies but it is always a separate constituent, never forming a morphological unit with the noun' (1986:106). The data in (5)-(8) illustrates a well-known general Tukanoan property of NCL: classifiers are generally suffixed to the nouns they classify. ${ }^{12}$

\footnotetext{
${ }^{12}$ See examples (15) and (16) for a case in Piratapuya where the NCL does not suffix the noun.
} 
Wilson Silva \& Joshua Bowles

\author{
Wanano $^{13}$ \\ (5) pari-taro \\ lake-NCLlake \\ 'lake'
}

Desano $^{15}$

(6) papera-turi

paper-NCL $\mathbf{L}_{\text {stack }}$

'paper'

Karapanã $^{16}$

(7) yo-ki

wood-NCL $\mathbf{L}_{\text {tree }}$

'tree'

Barasano $^{18}$

(8)
sudi-hãi
clothing-NCL $\mathbf{L}_{\text {flat,thin }}$
'cloth'

Claim (ii) - 'all occurrences of two generic nouns [NCL] in a noun phrase must involve one inherent nature term and one function/use classifier' (Dixon 1982:192). In ET languages some examples of the co-occurrence of NCL bring into question the intuitive classification of them as inherent or functional. The semantics are not clear and we are cautious in claiming that classifier languages restrict the co-occurrence of two noun-classifiers to inherent and functional. ${ }^{19}$ The data we present in (9)-(11) show that defining co-occurring NCLs as functional or inherent is problematic. It is not clear whether physical (shape/type) is a function or the inherent nature of the noun being classified, though shape/type would seem to involve inherent nature.

\footnotetext{
${ }^{13}$ Data from Stenzel (2004:147).

${ }^{15}$ Data from Miller (1999:40).

${ }^{16}$ Data from Silva (2006, fieldwork notes).

${ }^{18}$ Data from Jones and Jones (1992:57).

${ }^{19}$ The notion of "inherent" classifier compared to "function/use" classifier (Dixon 1982:192-205) seems to be a matter of interpretation of the linguist's classification of the use of native speaker lexical terms. The actual classification of objects in the world as either functional or inherent is determined by the world-view of the speakers themselves. For example, Dixon lists the Yidiny terms buri 'fire' and walba 'stone' as inherent classifiers without any argument for why exactly fire and stone are not functional in Ydiny. One must assume, then, that the classification of 'fire' and 'stone' is determined by the culture and world-view of the speakers. Thus, what is inherent in one culture may be functional in another. No standard for the linguistic determination of "inherent" can be possible in the absence of a coherent and applicable semantic theory.
} 
Kubeo $^{20}$

(9) hia-jo-ku

river-NCL $L_{\text {slender.pointed.cylindrical }}-\mathrm{NCL}_{\mathbf{h u m p} . \text { shaped }}$

'canoe'

(10) hia-jo-we

river-NCL $\mathbf{L}_{\text {slender.pointed.cylindrical }} \mathbf{N C L}_{\text {flat.thin }}$

'(canoe) paddle'

Wanano $^{21}$

(11) yukt-kt-phi

tree-NCL $\mathbf{L}_{\text {tree }}-\mathrm{NCL}_{\text {long,flat-blade.like }}$

'woden knife'

Claim (iii)- 'Noun classifier systems have a... large preference for one semantic cluster, that of material' (Grinevald 2000:73). In her study of the morphosyntactic typology of classifiers, Grinevald suggests that there is 'a semanticmorphosyntactic correlation, with a preference in numeral classifiers for the physical semantic cluster, in noun classifier, for the material semantic cluster...' (Grinevald 2000:72; c.f. Table 1 in this paper). However, in ET languages the NCL also shows preference for encoding the physical semantic cluster (type/shape) as well to the material semantic cluster (material/essence). Examples (12) - (14) illustrate the use of physical semantic cluster (type/shape) with NCL.

Piratapuya $^{22}$

$\begin{array}{ll}\text { a. } & \text { bisí doto } \\ & \text { vine } \text { NCL }_{\text {bundle }} \\ & \text { 'a bundle of vine' }\end{array}$

Barasano $^{23}$
(13)

$\begin{array}{ll}\text { a. } & \text { sudi-hãi } \\ & \text { clothing-NCL } \\ \text { 'clat/thin }\end{array}$
b. ohó too banana $\mathbf{N C L}_{\text {bunch }}$ 'a bunch of bananas'

b. $\quad b \sim$ eka-bo

ant-NCL $\mathbf{L}_{\text {dome }}$ 'ant hill'

\footnotetext{
${ }^{20}$ Data from Morse and Maxwell (1999:75).

${ }^{21}$ Data from Stenzel (2004:145).

${ }^{22}$ Data from Ball (2004:1).

${ }^{23}$ Data from Jones and Jones (1991:57-58).
} 
Wilson Silva \& Joshua Bowles

Tukano $^{24}$

(14) a.

$$
\begin{aligned}
& \text { nuri-gi }^{25} \\
& \text { penis-NCL } \\
& \text { 'penis' }
\end{aligned}
$$

b. $\quad$ uyu-gi

avacado-NCL stright/wood $_{\text {w }}$

'avacado tree'

\section{Conclusions and General Implications}

In conclusion we restate our findings. Besides being a separate word (as in some Austronesian, Australian and Mayan languages), NCLs in ET languages can also be bound morphemes. ET languages show evidence that two inherent NCLs may co-occur with a noun, dependent on whether one considers shape as an inherent feature and how exactly one assigns the distribution of 'function' to co-occurring NCLS. Regarding the prototypical typology of NCL proposed in Craig (1992) and Grinevald $(2000,2002)$ we have suggested an alternative (Table 2). Extending the semantic domain of NCL to include shape and type as well as allowing the NCL to be suffixed to the noun accounts for the examples in ET languages.

Questions remain about the role that NCL play in the agreement systems of ET languages. The view that NCLs should be placed somewhere in between lexical items and gender agreement items on a grammaticalization continuum implies that NCL could potentially play a role in the gender agreement (c.f. Barnes 1990; Gomez-Imbert 1996, 2006). Questions also remain about whether or not shape can be considered 'inherent,' and if so, in what way. It will be important to analyze data from discourse narratives and dialogues so we are able to account for the semantic and grammatical function of NCLs in a discourse context.

\section{References}

Aikhenvald, Alexandra. 2000. Classifiers: A Typology of Noun Categorization Devices. Oxford Studies in Typology and Linguistic Theory. Oxford: Oxford University.

Press.

Allan, K. 1977. Classifiers. Language 53: 284-310.

Ball, Christopher. 2004. An Automodular Approach to Noun Classifiers in Piratapuya (E. Tukanoan). Proceedings of the $30^{\text {th }}$ Annual Meeting of the Berkeley Linguistics Society, 1-10. Berkeley, CA: Berkeley Linguistics Society.

Barnes, Janet. 1990. Classifiers in Tuyuca. In Doris L. Payne, ed., Amazonian Linguistics: Studies in Lowland South American Languages, 273-92. Austin: University of Texas Press.

\footnotetext{
${ }^{24}$ Data from Ramirez (1997:213).

${ }^{25}$ The NCL suffix - gi "rectilinear/straight" refers to all type of trees or bushes except the palm and banana trees and also to all objects that are generally long and straight (Ramirez 1997:213).
} 
The Eastern Tukanoan Languages and the Typology of Noun Classifiers

Berlin, B. 1968. Tzeltal Numeral Classifiers: A Study in Ethnographic Semantics. The Hauge: Mouton.

Burling, R. 1965. How to Choose a Burnese Numeral Classifier. In M.E. Spiro, ed., Context and Meaning in Cultural Anthropology, in Honor of A. Irving Hallowell, 243-64. New York: Free Press.

Craig, C.G. 1986a. Jacaltec noun classifiers: a study in language and culture. In C.G. Craig ed., Noun Classes and Categorization: Proceedings of a Symposium on Categorization and Noun Classification, Eugene, Oregon, October 1983, 295-363. Amsterdam: John Benjamins.

Craig, C.G., ed. 1986b. Noun Classes and Categorization: Proceedings of a Symposium on Categorization and Noun Classification, Eugene, Oregon, October 1983. Amsterdam: John Benjamins.

Craig, C.G. 1992. Classifiers in a functional perspective. In M. Fortescue, P. Harder and L. Kristoffersen, eds., Layered Structure and Reference in Functional Perspective, 277-301. Amsterdam: John Benjamins.

Criswell, Linda and B. Brandrup. 2000. Un Bosquijo Fonológico y Gramatical del Siriano. In Maria Stella G. de Pérez and Maria Luiza R. de Montes, eds., Lenguas Indígenas de Colombia: Una Visión Descriptiva, 395-415. Santafé de Bogotá: Instituto Caro y Cuervo.

Denny, J.P. 1976. What are Noun Classifiers Good For? Papers from the Annual Regional Meeting of the Chicago Linguistic Society 12: 122-32.

Derbyshire, D.C. and D.L. Payne. 1990. Noun Classification Systems of Amazonian Languages. In Doris L. Payne, ed., Amazonian Linguistics: Studies in Lowland South American Indian Languages, 243-71. Austin: University of Texas Press.

Dixon, R.M.W. 1982. Where Have all the Adjectives Gone? And Other Essays in Semantics and Syntax. Berlin: Mouton.

Dixon, R.M.W. 1986. Noun Classes and Noun Classification in Typological Perspective. In Colette Craig, ed., Noun Classes and Categorization: Proceedings of a Symposium on Categorization and Noun Classification, Eugene, Oregon, October 1983, 105-112. Amsterdam: John Benjamins.

Fergunson, Judith, C. Hollinger, L. Criswell and N. Morse. 2000. El Cubeo. In Maria Stella G. de Pérez and Maria Luiza R. de Montes, eds., Lenguas Indígenas de Colombia: Una Visión Descriptiva, 357-70. Santafé de Bogotá: Instituto Caro y Cuervo.

Gomez-Imbert, Elza. 2007. Tucanoan Nominal Classification: The Tatuyo System. In W. Leo Wetzels ed., Language Endangerment and Endangered Languages: Linguistic and Anthropological Studies with Special Emphasis on the Languages and Cultures of the Andean-Amazonian Border Area. Indigenous Languages of Latin America Series (ILLA). Publications of the Research School of Asian, African and Amerindian Studies (CNWS). Leiden University, the Netherlands. 
Grinevald, Colette. 2000. A Morphosyntactic Typology of Classifiers. In Gunter Senft, ed., Systems of Nominal Classification, 50-92. Language Culture and Cognition 4. Cambridge University Press.

Grinevald, Colette. 2002. Making Sense of Nominal Classification Systems: Noun Classifiers and the Grammaticalization Variable. In Ilse Wischer an G. Diewald, eds., New Reflections on Grammaticalization, 259-75. Amsterdam/Philadelphia: John Benjamins.

Jones, Wendell, and Paula Jones. 1991. Barasano Syntax. Dallas: Summer Institute of Linguistics and the University of Texas at Arlington.

Kinch, Pamela G. and R. A. Kinch. 2000. El Yurutí. In Maria Stella G. de Pérez and Maria Luiza R. de Montes, eds., Lenguas Indígenas de Colombia: Una Visión Descriptiva, 469-87. Santafé de Bogotá: Instituto Caro y Cuervo.

Metzger, Ronald G. 1981. Gramatica Popular del Carapana. Bogotá, Colombia: Instituto Lingüístico de Verano.

Miller, Marion. 1999. Desano Grammar. Dallas: Summer Institute of Linguistics and the University of Texas at Arlington.

Morse, Nancy, and Michael Maxwell. 1999. Cubeo Grammar. Dallas: Summer Institute of Linguistics and the University of Texas at Arlington.

Ramirez, Henri. 1997. A Fala Tukano dos Ye'pâ-Masa, Tomo I: Gramática. Manaus: Inspetoria Salesiana Missionária da Amazônia.

Silva, Wilson. [manuscript]. Fieldwork notes on Karapanã (Summer 2006).

Sorensen, A. P. Jr. 1969. Morphology of Tucano. Ph.D. diss, Columbia University.

Stenzel, Kristine (2004). A Reference Grammar of Wanano. Ph.D. diss, University of Colorado.

Strom, Clay. 1992. Retuarã Grammar. Dallas: Summer Institute of Linguistics and the University of Texas at Arlington.

Welch, Beth and B. West. 2000. El Tucano. In Maria Stella G. de Pérez and Maria Luiza R. de Montes, eds., Lenguas Indígenas de Colombia: Una Visión Descriptiva, 419-36. Santafé de Bogotá: Instituto Caro y Cuervo.

Wilson Silva and Joshua Bowles

Department of Linguistics

University of Utah

255 S. Central Campus Dr. Rm 2300

Salt Lake City, UT 84112

wilson.silva@utah.edu

bowles.j.ling@utah.edu 